\title{
Influence of different rotor magnetic circuit structure on the performance of permanent magnet synchronous motor
}

\author{
Hongbo QiU, Wenfei Yu, CunXiang Yang, Ran Yi \\ College of Electric and Information Engineering \\ Zhengzhou University of Light Industry \\ Zhengzhou 450002, China \\ e-mail:yiranjob@163.com
}

(Received: 09.01.2017, revised: 07.03.2017)

\begin{abstract}
In order to compare the performance difference of the permanent magnet synchronous motors (PMSM) with different rotor structure, two kinds of rotor magnetic circuit structure with surface-mounted radial excitation and tangential excitation are designed respectively. By comparing and analyzing the results, the difference of the motor performance was determined. Firstly, based on the finite element method (FEM), the motor electromagnetic field performance was studied, and the magnetic field distribution of the different magnetic circuit structure was obtained. The influence mechanism of the different magnetic circuit structure on the air gap flux density was obtained by using the Fourier theory. Secondly, the cogging torque, output torque and overload capacity of the PMSM with different rotor structure were studied. The effect mechanism of the different rotor structure on the motor output property difference was obtained. The motor prototype with two kinds of rotor structure was manufactured, and the experimental study was carried out. By comparing the experimental data and simulation data, the correctness of the research is verified. This paper lays a foundation for the research on the performance of the PMSM with different magnetic circuit structure.
\end{abstract}

Key words: air gap flux density, cogging torque, magnetic circuit structure, overload capacity, permanent magnet synchronous motor

\section{Introduction}

The permanent magnet motor has the advantages of simple structure, high power density and high efficiency, which has been widely used in wind power generation, transportation, industrial processing and aerospace $[1,2]$. There are many kinds of rotor magnetic circuit structure of the PMSM. The permanent magnet of the surface-mounted permanent magnet (SPM) motor is installed on the rotor surface, and the radial excitation mode is generally adopted. Its permanent magnet processing and installation is simple. The sleeve is usually added to the outside of the permanent magnet to prevent the permanent magnet from being thrown out due 
to high speed rotation. The permanent magnet of an interior permanent magnet (IPM) motor is buried in the rotor. The excitation mode is flexible and it is divided into three types: tangential, radial and hybrid. The rotor magnetic circuit structure has influence on the machining process, application situation and performance, and it is very important to study the influence of the rotor magnetic pole structure on the motor performance.

In recent years, there are many experts and scholars who study the performance difference of the motor with different rotor magnetic circuit structure, and some results have been obtained. Reference [3] proposed a new type of magnetic circuit structure motor, and the torque, magnetic flux density and economy of the different magnetic circuit structures were compared. Reference [4] adopted an equivalent magnetic circuit method to research on the electromagnetic characteristics of the surface-mounted and the interior hybrid PMSM. Some scholars have studied two kinds of rotor magnetic circuit structures, such as surface mounted and interior, but few have studied the motor performance with different rotor magnetic circuit structure under the same stator parameters, motor volume and output power condition. Reference [5] analyzed the performance of SPM and IPM motors under the effect of an inter-turn short circuit fault. The SPM and IPM motors were compared in electric traction application [6]. Reference [7] proposed a maximum current limit for motor designs to reduce the impact of irreversible demagnetization of the interior and surface-type permanent magnets brushless DC motor. Reference [8] proposed a method to quantify the various sources of the torque ripple and modifies the existing DQ-model to enhance the modeling capabilities for both surfacemount and interior PMSMs. In reference [9], the loss and temperature fields of an SPM and an IPM are compared, but the electromagnetic field and motor performance were not studied. There is little study of the electromagnetic field and overload performance with different magnetic circuit structures under the same motor volume and output power condition. In this paper, the electromagnetic field, air gap flux density, output torque and overload capacity were studied under the same stator parameters, motor volume and output power condition.

Based on the FEM, the electromagnetic field performance of the motor with different rotor magnetic circuit structure was studied, and the magnetic field distribution of the motor with the different magnetic circuit structure was obtained. By using the Fourier theory, the influence mechanism of the different magnetic structure on the motor air gap magnetic flux harmonic contents was obtained. Next, the cogging torque, the output torque and the overload capacity of the PMSM with different rotor magnetic circuit structure were studied. The effect mechanism of the different rotor magnetic circuit structure on the motor output property difference was obtained. The prototype of two kinds with rotor structure was manufactured, and the experimental study was carried out. By comparing the experimental data and simulation data, the correctness of the research is verified. This paper lays a foundation for the research on the performance of a permanent magnet motor with different magnetic circuit structure.

\section{Model and parameters}

In order to explore the influence mechanism of the different rotor magnetic circuit structure on motor performance, two types of rotor structure motor, which are SPM motor and IPM 
motor are designed respectively. The two motor stator parameters, motor volume and output power are completely consistent. The motor FEM is shown in Fig. 1 and the motor basic parameters are shown in Table 1.

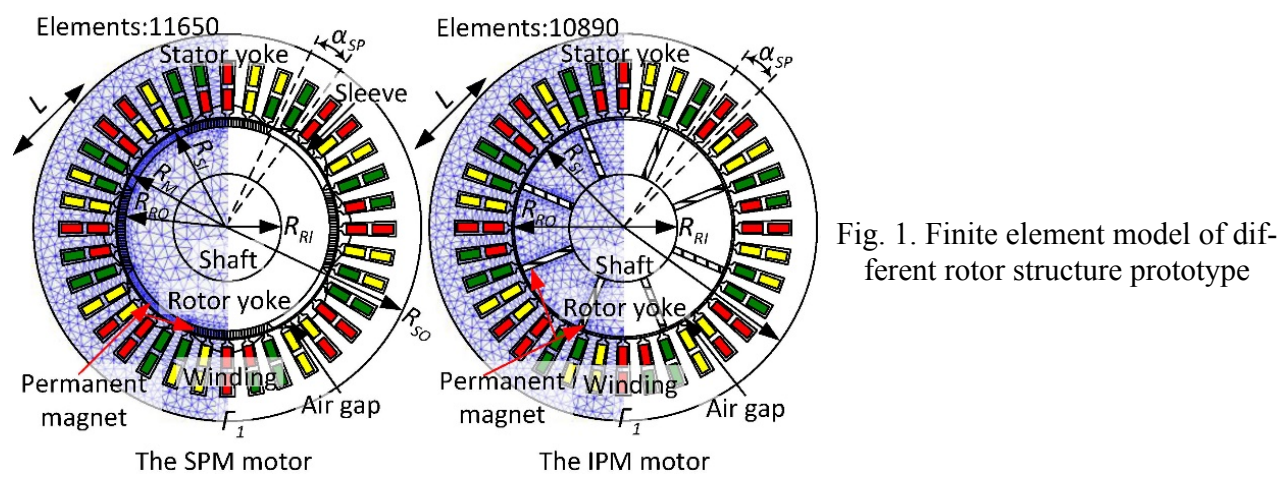

Table 1. Parameters of the model

\begin{tabular}{l|c|c|c}
\hline \multicolumn{1}{c|}{ Parameters } & SPM & IPM & Unit \\
\hline Rated power & 10 & 10 & $\mathrm{~kW}$ \\
\hline Rated speed & 2000 & 2000 & $\mathrm{r} / \mathrm{min}$ \\
\hline Pole number & 8 & 8 & \\
\hline Stator external diameter & 180 & 180 & $\mathrm{~mm}$ \\
\hline Stator inner diameter & 103 & 103 & $\mathrm{~mm}$ \\
\hline Iron core axial length & 102 & 102 & $\mathrm{~mm}$ \\
\hline Slot number & 36 & 36 & \\
\hline Conductors per slot & 20 & 20 & \\
\hline Number of parallel branches & 1 & 1 & \\
\hline Thickness of permanent magnet & 3 & 3 & $\mathrm{~mm}$ \\
\hline Sectional area of permanent magnet & 108.9 & 75 & $\mathrm{~mm}$ \\
\hline Sleeve external diameter & 101.4 & - & $\mathrm{mm}$ \\
\hline Winding connection type & $\mathrm{Y}$ & $\mathrm{Y}$ & \\
\hline
\end{tabular}

In this paper, the two-dimensional (2D) cross section of the machine perpendicular to an axial direction is selected as the analysis model, as shown in Fig. 1. The transient mathematical model for a 2D electromagnetic field calculation would be (1), in which the permanent magnet is simulated by a current density source [10].

$$
\left\{\begin{array}{c}
\Omega: \frac{\partial}{\partial x}\left(\frac{1}{\mu} \frac{\partial A_{z}}{\partial x}\right)+\frac{\partial}{\partial y}\left(\frac{1}{\mu} \frac{\partial A_{z}}{\partial y}\right)-\sigma \frac{\partial A_{z}}{\partial t}=-J_{z}, \\
\Gamma_{1}: A_{z}=0 \\
\Gamma_{1}: \frac{1}{\mu_{1}} \frac{\partial A_{z}}{\partial n}-\frac{1}{\mu_{2}} \frac{\partial A_{z}}{\partial n}=J_{s},
\end{array}\right.
$$


where: $\Omega$ is the calculation region, $A_{z}$ and $J_{z}$ represent the magnetic vector potential and the source current density in the $z$-axial component respectively (in $\mathrm{A} / \mathrm{m}^{2}$ ). $J_{s}$ is the equivalent face current density of the permanent magnet (in $\mathrm{A} / \mathrm{m}^{2}$ ), $\sigma$ is the conductivity (in $\mathrm{S} / \mathrm{m}$ ). $\Gamma_{1}$ is the parallel boundary conditions, $\Gamma_{2}$ is the permanent magnet boundary condition, $\mu_{1}$ and $\mu_{2}$ represent the relative permeability respectively.

During the electromagnetic study, combined with the actual structure of the motor, in order to simplify the calculation and analysis, following assumptions are proposed [11].

1)A displacement current and skin effect in the stator windings are ignored.

2) Materials are isotropic. Permeability and conductivity of the materials are constant except the stator core and the rotor yoke.

3) The displacement current is ignored.

No-load electromotive force (EMF) is an important parameter for the PMSM design and control. It not only affects the motor operating state such as the magnetic state, demagnetization state, but also determines the size of the motor no-load current and loss. In order to verify the correctness of the motor model, the prototypes is manufactured and the back EMF, load experiment is performed. The experiment adopts MX30 Ametek variable-frequency power, Magtrol dynamometer machine, YOKOGAWA power analyzer, DSP data acquisition system and other equipment to test the motor electromagnetic field and temperature field. The test platform of the prototype is shown in Fig. 2.

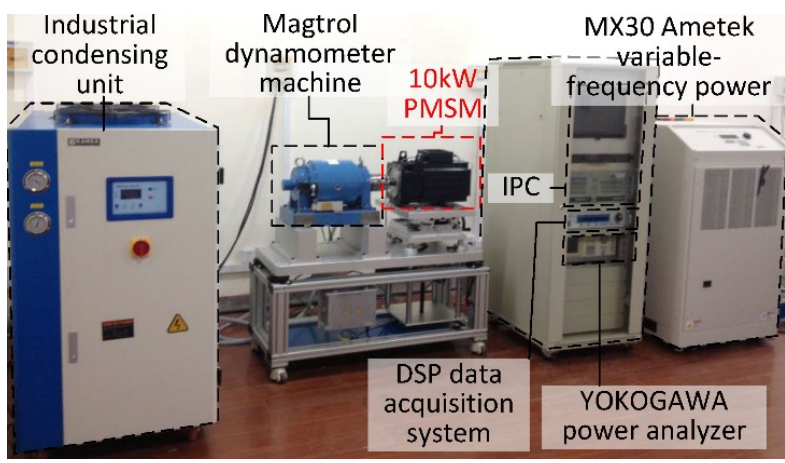

Fig. 2. Test platform of the prototype

Table 2. Test data and calculation results of SPM motor

\begin{tabular}{c|c|c|c}
\hline Speed & Experimental & Simulation & Deviation \\
\hline $750 \mathrm{rpm}$ & $118.8 \mathrm{~V}$ & $116.7 \mathrm{~V}$ & $1.77 \%$ \\
\hline $2000 \mathrm{rpm}$ & $316 \mathrm{~V}$ & $311.4 \mathrm{~V}$ & $1.46 \%$ \\
\hline
\end{tabular}

Table 3. Test data and calculation results of SPM motor at different conditions

\begin{tabular}{c|c|c|c}
\hline Torque & Experimental current & Simulation current & Deviation rate \\
\hline $25 \mathrm{~N} \cdot \mathrm{m}$ & $10.62 \mathrm{~A}$ & $10.23 \mathrm{~A}$ & $3.8 \%$ \\
\hline $36.4 \mathrm{~N} \cdot \mathrm{m}$ & $15.3 \mathrm{~A}$ & $15.4 \mathrm{~A}$ & $0.6 \%$ \\
\hline $47.7 \mathrm{~N} \cdot \mathrm{m}$ & $19.3 \mathrm{~A}$ & $19.6 \mathrm{~A}$ & $1.6 \%$ \\
\hline
\end{tabular}




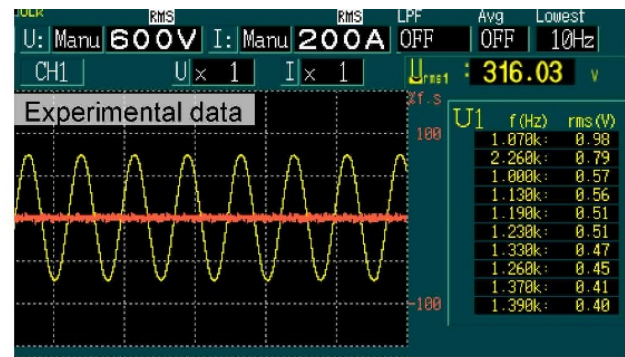

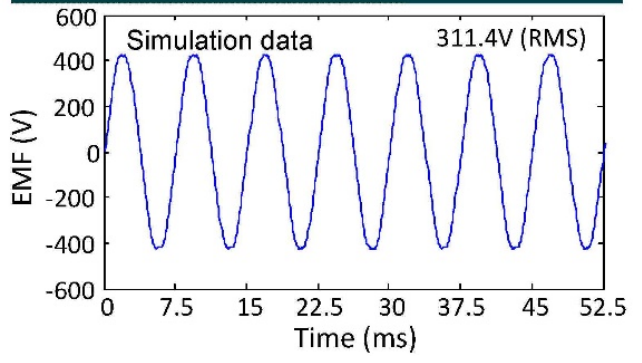

(a)
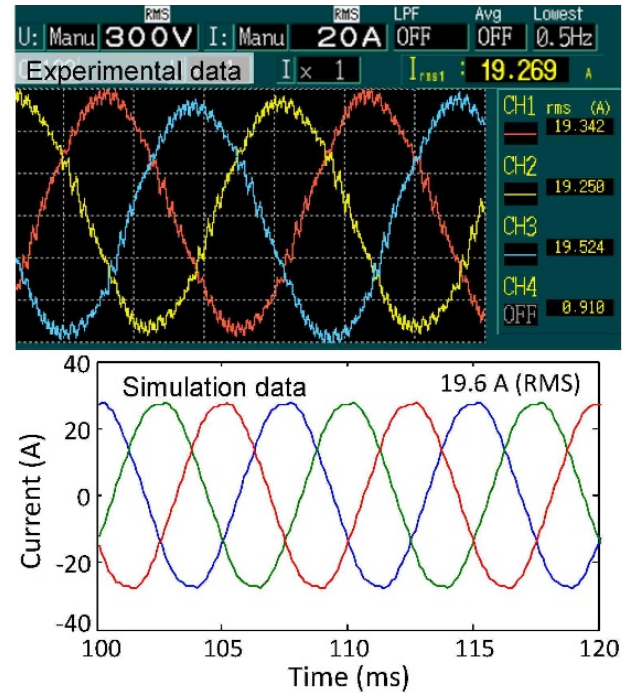

(b)

Fig. 3. Comparison between the data of simulation and experiment: the SPM motor noload back EMF data (a); the SPM motor three-phase current data (b)

The simulation and experimental noload back EMF data of the SPM motor are compared as shown in Table 2. Fig. 3a is the back EMF experiment and the simulation data when the speed is $2000 \mathrm{rpm}$. The experimental and simulation RMS values are $316 \mathrm{~V}$ and $311.4 \mathrm{~V}$, respectively. Due to the influence of the permanent magnet shape, the permanent magnet magnetic field contains various harmonics. The magnitude of the back EMF can reflect the permanent magnet excitation performance. The RMS value and the entire harmonic content of the back EMF are taken into account. The back EMF is a line voltage. Test data and calculation results of the SPM motor three-phase current when the motor operates at different conditions are shown in Table 3.

Fig. $3 \mathrm{~b}$ is the three-phase current experiment and the simulation data when the motor output torque is $47.7 \mathrm{~N} \cdot \mathrm{m}$. During the motor actual operation, because of the controller poor filtering effect, the output current harmonic content is large. The fundamental content of the motor experimental current is $19.2 \mathrm{~A}$. The fundamental content of the motor simulation current is 19.6 A. The fundamental content of the simulated current is consistent with that of the experiment. The experimental and simulation RMS values are $19.3 \mathrm{~A}$ and $19.6 \mathrm{~A}$, respectively. The RMS value and the entire harmonic content of the phase current are taken into account. There is a deviation between the experiment current and the simulation current. The deviation is below $5 \%$, which can satisfy the practical demand of the project. The simulation noload back EMF data of the IPM motor is the same as the data of the SPM motor. The correctness of the motor design and the established motor model are verified. 


\section{Electromagnetic field analysis}

An electromagnetic field is the medium of the electromechanical energy conversion. It is the most important factor under motor operation. In the motor design and research, it is very important to analyse the motor electromagnetic field. The research methods of the electromagnetic field include the analytical method and the FEM. When using the analytic method to calculate an electromagnetic field, the state of the local electromagnetic field in the motor cannot be taken into account and the transient changes of the motor magnetic field cannot be analyzed. When using the FEM to calculate an electromagnetic field, not only those problems can be overcome, but also the complex structure of alveolar can be more comprehensive to be considered and the result is more accurate. In this paper, the motor transient magnetic field is calculated by using the time stepping FEM.

\subsection{The magnetic field distribution}

In the motor transient field finite element calculation, the path of the magnetic field can be expressed visually by the magnetic line of force. The motor magnetic field intensity changes can be clearly reflected by the motor magnetic density distribution diagram. The electromagnetic field distribution is shown in Fig. 4.
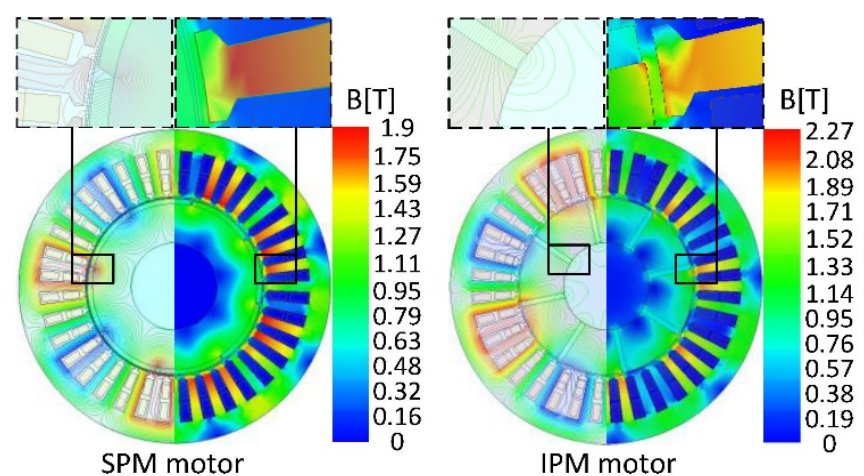

Fig. 4. The electromagnetic field distribution

The motor rotor pole number is 8 . From Fig. 4, it can be seen clearly that the magnetic field in the circumferential direction distribution is symmetrical in either the SPM motor or the IPM motor. The variation of the magnetic flux density at 5 points in a cycle is obtained as shown in Fig. 5. The 5 points are the rotor yoke, the rotor edge near the air gap, the stator tooth edge near the air gap, the middle part of the stator tooth and the stator yoke, respectively. Combined with the above back EMF simulation and measurement results, it can be known that the stator side magnetic field strength of the two motors is approximately the same. The difference in the rotor side is obvious.

There is almost no magnetic leakage in the SPM motor rotor magnetic field. Because of the IPM motor special structure, magnetic flux leakage occurs at the permanent magnet corner near the shaft, as shown in Fig. 4. The magnetic isolation bridge should be added to reduce the leakage flux. The magnetic density instantaneous value at the corner of the rotor silicon steel 
sheets adjacent to the permanent magnet reaches $2.27 \mathrm{~T}$. In order to study the variation of the magnetic flux density with time, the magnetic flux density in this region over a time period is obtained, as shown in Fig. 5 of the point B. It is concluded that the maximum value of the IPM motor magnetic flux density is only instantaneous and will not cause damage to the rotor.
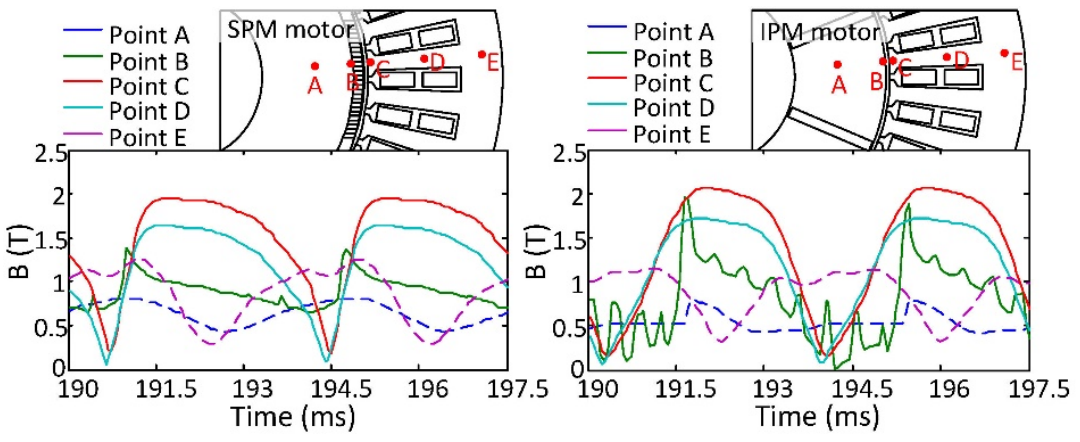

Fig. 5. The variation of the magnetic density with time

The SPM motor maximum magnetic flux density appears in the motor teeth. It can be seen that the teeth magnetic saturation is serious, the maximum value of the magnetic flux density reaching $1.9 \mathrm{~T}$. Because of the high magnetic density on the rotor side of the IPM motor, the range of the magnetic flux density fluctuation is larger than that of the SPM motor.

\subsection{The air gap flux density}

Different from the traditional electromagnetic motor, the PMSM magnetic field is excited by permanent magnets. The air gap magnetic field is the hub of the electromechanical energy conversion. The harmonic orders and contents of the air gap magnetic field directly affects the induced EMF and the output torque, which can affect the motor performance, so it is necessary to study it thoroughly.

In order to further study the excitation performance and the air gap magnetic flux harmonic content difference of the SPM motor and IPM motor. The air gap flux density of the SPM motor and IPM motor is extracted respectively. The harmonic content of the air gap magnetic flux density is obtained by the Fourier decomposition theory [12]. The air gap magnetic dense waveforms and the Fourier decomposition results of the air gap magnetic density under a pair of poles are shown in Fig. 6.

The motor pole pairs are 4 . Because the motor structure is completely symmetrical, the magnetic field distribution of each pair of poles is exactly the same. The motor magnetic field is divided into 4 identical magnetic fields along the circumference. The air gap flux density of the IPM motor is higher than that of the SPM motor as shown in Fig. 6. The magnetic field range under each magnetic pole pair of the IPM motor is lower than that of the SPM motor.

In order to accurately compare the harmonic content difference of the SPM motor with the IPM motor, the air gap magnetic flux under a pair of poles is obtained and the harmonic decomposition is carried out by using the Fourier decomposition theory. It is found that the 
fundamental content and the 3rd harmonic content of the SPM motor air gap magnetic flux density are larger than those of the IPM motor. The 7th, 9th, 11th, 13th, 19th harmonic content of the IPM motor air gap magnetic flux density are greater than those of the SPM motor.

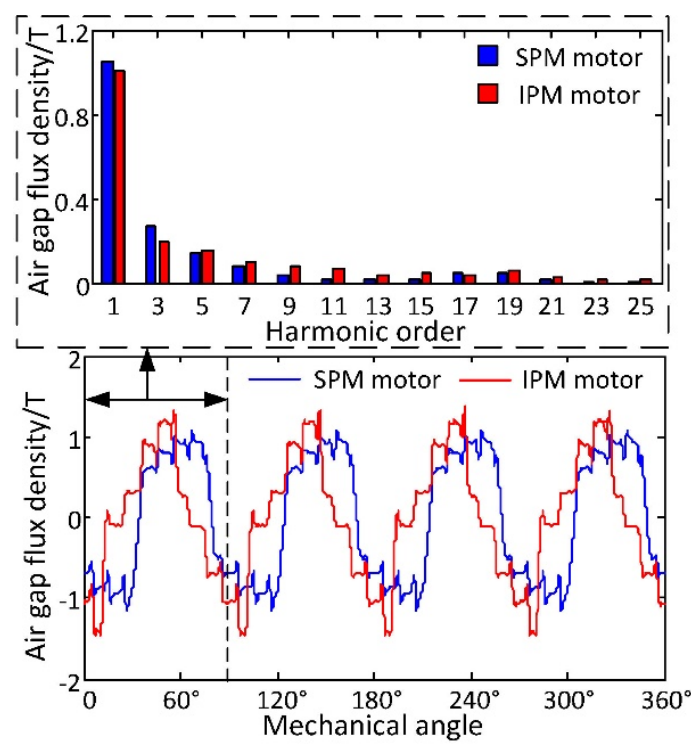

Fig. 6. The air gap magnetic flux of different pole structure

\subsection{The cogging torque}

The cogging torque is the torque caused by mutual attraction between the stator iron core and the permanent magnet when the armature winding is not energized. The motor performance is reduced by the cogging torque. The motor electromagnetic noise and vibration are caused by the cogging torque especially in the application of low speed and high torque. The cogging torque is one of the most important performance parameter when the motor is designed. The cogging torque waveform of two different magnetic circuit structures is compared in Fig. 7.

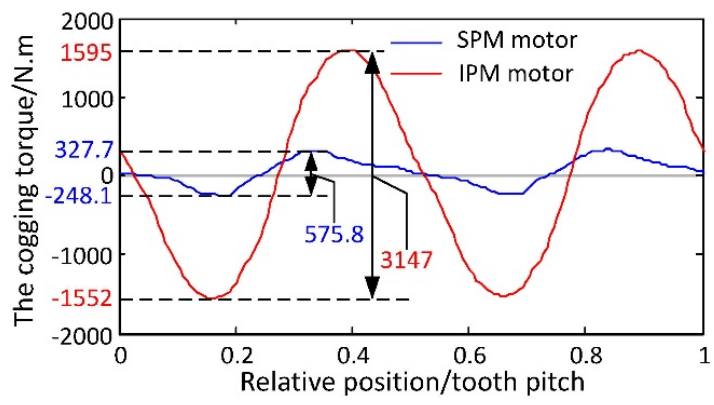

Fig. 7. The cogging torque waveform of SPM motor and IPM motor

Fig. 7 shows, the cogging torque fluctuation amplitude of the SPM motor is less than that of the IPM motor. Because the permanent magnet of SPM motor processing and installation is 
convenient, the permanent magnet eccentricity optimization is usually performed to obtain more sinusoidal air gap magnetic field that conducive to reduce the cogging torque.

The SPM motor cogging torque peak value is $327.7 \mathrm{mN} \cdot \mathrm{m}$ and the maximum fluctuation amplitude is $1.2 \%$ of the rated output torque. The IPM motor cogging torque peak value is $1595 \mathrm{mN} \cdot \mathrm{m}$ and the maximum fluctuation amplitude is $6.59 \%$ of the rated output torque. The cogging torque value of the IPM motor is larger than that of the SPM motor. The follow-up work will focus on the optimization of the IPM motor cogging torque.

\subsection{Torque ripple and overload capacity analysis}

The output torque is not completely constant when the motor under load operation. Usually, the torque ripple is used to characterize torque variations. The torque fluctuation is influenced by the cogging torque, electromagnetic moment fluctuation, armature reaction and mechanical technology. The torque fluctuation is closely related to the motor working ability, energy consumption, efficiency and service period, so it is very important to study the torque ripple.

The torque of the SPM motor and the IPM motor is calculated by the FEM, and the motor torque fluctuation is obtained when the motor under rated operation as shown in Fig. 8.

The torque ripple coefficient is used to measure the motor torque ripple when analyzing the PMSM torque ripple [13].

$$
\delta=\sqrt{\sum_{1}^{\infty}\left(T_{i \max }-T_{\text {avg }}\right)^{2}+\sum_{1}^{\infty}\left(T_{i \min }-T_{\text {avg }}\right)^{2}} \times 100 \%,
$$

where: $\delta$ is the torque ripple coefficient, $T_{i \max }$ and $T_{i \min }$ represent the maximum and minimum values of the torque ripple in the $i$-th cycle respectively, $T_{\text {avg }}$ is the torque average value in the $i$-th cycle, $n$ is the number of the computation cycles.

The SPM motor output torque is the same as the IPM motor's, the value is $47.75 \mathrm{~N} \cdot \mathrm{m}$. The maximum torque fluctuation amplitude of the SPM motor is $3.7 \mathrm{~N} \cdot \mathrm{m}$ and the torque ripple coefficient is $5.47 \%$. The maximum torque fluctuation amplitude of the IPM motor is $4.69 \mathrm{~N} \cdot \mathrm{m}$ and the torque ripple coefficient is $6.96 \%$. Because the cogging torque and the induced EMF harmonic content of the IPM is larger than that of the SPM motor, the IPM motor torque ripple is larger than that of the SPM motor.

It can be seen from the torque fluctuation curve that the torque ripple is regular pulsation in one cycle. The torque ripple frequency of the IPM motor is much larger than that of the SPM motor within the same time.

In actual operation, the motor overload capability is a key index of motor performance. Therefore, based on the study of the electromagnetic torque, the following will further study on the motor overload capacity.

The PMSM electromagnetic torque formula as [14]:

$$
T_{e m}=\frac{P_{e m}}{\Omega}=\frac{m p E_{0} U}{\omega X_{\mathrm{d}}} \sin \theta+\frac{m p U^{2}}{2 \omega}\left(\frac{1}{X_{\mathrm{q}}}-\frac{1}{X_{\mathrm{d}}}\right) \sin 2 \theta,
$$



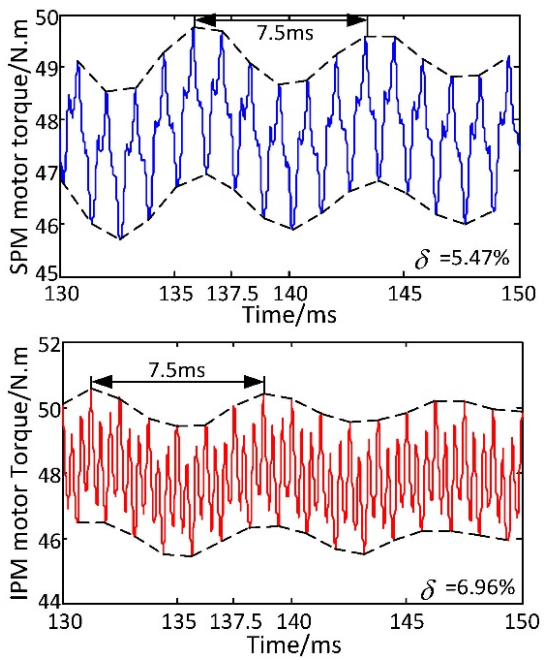

Fig. 8. The motor output torque fluctuation

where $m$ is the number of motor phases, $p$ is the number of the pole pairs, $U$ is the input phase voltage RMS considering the entire harmonic content, $E_{0}$ is the noload induced EMF RMS considering the entire harmonic content, $\omega$ is the electric angular velocity, $X_{\mathrm{d}}$ is the direct axis reactance, $X_{\mathrm{q}}$ is the quadrature axis reactance, $\theta$ is the power angle. The motor reactance parameters and the maximum output torque are shown in Table 4.

Table 4. The motor maximum output torque

\begin{tabular}{c|c|c|c}
\hline Parameters & Analytic calculation & Finite element calculation & Deviation \\
\hline SPM motor & $143.5 \mathrm{~N} \cdot \mathrm{m}$ & $135.4 \mathrm{~N} \cdot \mathrm{m}$ & $5.98 \%$ \\
\hline IPM motor & $83.9 \mathrm{~N} \cdot \mathrm{m}$ & $73.3 \mathrm{~N} \cdot \mathrm{m}$ & $14.5 \%$ \\
\hline
\end{tabular}

The SPM motor direct axis reactance is equal to the quadrature axis reactance and the value is $3.51 \Omega$. The value of the maximum output torque calculated by the FEM is $135.4 \mathrm{~N} \cdot \mathrm{m}$ which is 2.8 times larger than that of normal operation. The value of the maximum output torque calculated by the analytic method is $143.5 \mathrm{~N} \cdot \mathrm{m}$. The deviation between the FEM data and the analytic method data is $5.98 \%$. The reason for the deviation is that the analytical calculation does not take into account the motor end leakage resistance.

The SPM motor direct axis reactance is $6.3 \Omega$ and the quadrature axis reactance is $9 \Omega$. The IPM motor quadrature axis reactance is larger than the direct axis reactance. Because the reluctance torque generated by the motor $\mathrm{d}$, q axis magnetic circuit asymmetry is a negative sine function, the torque angle on the torque angle characteristics is greater than 90 deg when the torque value is largest. The IPM motor power angle under rated operation condition is $52 \mathrm{deg}$. The IPM motor power angle is $107 \mathrm{deg}$ when the output torque value is largest. The value of the maximum output torque calculated by the FEM is $73.3 \mathrm{~N} \cdot \mathrm{m}$ which is 1.54 times larger than that of normal operation. The value of the maximum output torque calculated by 
the analytic method is $87.4 \mathrm{~N} \cdot \mathrm{m}$. The deviation between the FEM data and the analytic method data is $14.5 \%$. The reason for the deviation is that the analytical calculation does not take into account the motor leakage resistance. The SPM motor maximum output torque is 1.85 times larger than that of the IPM motor.

There are some limitations in the study, the starting process and speed regulation performance of the SPM motor and the IPM motor will be studied in the further research.

\section{Conclusions}

Due to the difference of the rotor structure between the SPM motor and the tangential magnetization IPM motor, the motor performances during the operation are different. In this paper, the PMSM performances with two kinds of rotor magnetic circuit structure are studied and the stator parameters, motor volume and output power are the same. The following conclusions are obtained.

1) The stator magnetic field strength of the motors with two rotor magnetic circuit structural is approximately the same. The difference in the rotor side is obvious. There is almost no magnetic leakage in the SPM motor rotor magnetic field. Because of the special structure of the IPM motor, magnetic flux leakage occurs at the permanent magnet corner near the shaft. The maximum value of magnetic flux density of the IPM motor is only instantaneous and will not cause damage to the rotor.

2) The air gap magnetic flux density of the IPM motor is higher than that of the SPM motor. The magnetic field range under each pair magnetic pole of the IPM motor is lower than that of the SPM motor. Beside the fundamental and the 3rd harmonic, the other times harmonic contents of the IPM motor air gap magnetic flux density are greater than those of the SPM motor. The cogging torque value of the IPM motor is 4.87 times larger than that of the SPM motor.

3) Because the cogging torque and the induced EMF harmonic content of the IPM motor are larger than that of the SPM motor, the IPM motor torque ripple is larger than that of the SPM motor. The torque ripple frequency of the IPM motor is much larger than that of the SPM motor within the same time. The SPM motor maximum output torque is 1.85 times larger than that of the IPM motor.

\section{Acknowledgments}

This work was supported in part by the National Natural Science Foundation of China under Grant 51507156, in part by the University Key Scientific Research Programs of Henan province under Grant 17A470005, in part by the Doctoral Program of Zhengzhou University of Light Industry under Grant 2014BSJJ042, in part by the Major Science and Technology Special Projects of Henan Province under Grant 161100211600, in part by the Graduate Scientific and Technology Innovation Foundation of Zhengzhou University of Light Industry under Grant 2016001, in part by the Scientific and Technological Projects of Zhengzhou under Grant 20150442, and in part by the Foundation for Key Teacher of Zhengzhou University of Light Industry. 


\section{References}

[1] Ogbuka C., Nwosu C., Agu M., Dynamic and steady state performance comparison of line-start per manent magnet synchronous motors with interior and surface rotor magnets, Archives of Electrical Engineering, vol. 65, no. 1, pp. 105-116 (2016).

[2] Gómez D.J., Rodríguez A.L., Villar I. et al., Experimental validation of an enhanced permeance network model for embedded magnet synchronous machines, Electric Power Systems Research, vol. 140, pp. 836-845 (2016).

[3] Barcaro M., Bianchi N., Interior PM Machines Using Ferrite to Replace Rare-Earth Surface PM Machines, IEEE Transactions on Industry Applications, vol. 50, no. 2, pp. 979-985 (2014).

[4] Si J., He S., Cao W. et al., Electromagnetic characteristics analysis of surface-mounted and interior hybrid PMSM based on equivalent magnetic circuit method, IEEE International Conference on Electrical Machines and Systems, Hangzhou, China, pp. 1125-1131 (2014).

[5] Lai C., Balamurali A., Bousaba V. et al., Analysis of stator winding inter-turn short-circuit fault in interior and surface mounted permanent magnet traction machines, Transportation Electrification Conference and Expo, IEEE, Dearborn, MI, USA, pp. 1-6 (2014).

[6] Pellegrino G., Vagati A., Guglielmi P. et al., Performance Comparison Between Surface-Mounted and Interior PM Motor Drives for Electric Vehicle Application, IEEE Transactions on Industrial Electronics, vol. 59, no. 2, pp. 803-811 (2012).

[7] Kim H.K., Jin H., Dynamic characteristic analysis of irreversible demagnetization in SPM- and IPM- type BLDC motors, IEEE Energy Conversion Congress and Exposition, Montreal, QC, Canada, pp. 308313 (2015).

[8] Gebregergis A., Chowdhury M.H., Islam M.S. et al., Modeling of Permanent-Magnet Synchronous Machine Including Torque Ripple Effects, IEEE Transactions on Industry Applications, vol. 51, no. 1, pp. 21082114 (2013).

[9] Zhao N., Liu W., Loss calculation and thermal analysis of surface-mounted PM motor and interior PM motor, IEEE Transactions on Magnetics, vol. 54, no. 46, pp. 11 (2015).

[10] Weili L., Jing W., Xiaochen Z., Baoquan K., Loss calculation and thermal simulation analysis of high-speed PM synchronous generators with rotor topology, 2010 International Conference on Computer Application and System Modeling, Taiyuan, China, pp. 612616 (2010).

[11] Xia C., Li X., Z-Source Inverter-Based Approach to the Zero-Crossing Point Detection of Back EMF for Sensorless Brushless DC Motor, IEEE Transactions on Power Electronics, vol. 30, no. 3 , pp. 14881498 (2015).

[12] Witczak P., Kubiak W., Lefik M. et al., Modal-frequency spectrum of magnetic flux density in air gap of permanent magnet motor, Archives of Electrical Engineering, vol. 63, no. 1, pp. 2946 (2016).

[13] Qiu H., Yu W., Tang B. et al., Effects of driving modes on permanent magnet motor electromagnetic and temperature fields at limit conditions, The international journal for computation and mathematics in electrical and electronic engineering, vol. 35, no. 6, pp. 2045-2062 (2016).

[14] Chowdhury M.H., Modeling of faults in permanent magnet synchronous machines, 2016 IEEE Transportation Electrification Conference and Expo, Asia-Pacific (ITEC Asia-Pacific), Busan, South Korea, pp. 246250 (2016). 